\title{
Research Paper: Prevalence of Flat Foot in Primary School Students Aged 7-12 Years, in Zanjan City, Iran
}

\author{
Marzieh Pashmdarfard ${ }^{1,2}$, Malek Amini ${ }^{*}$, Seyyed Hassan Sanei ${ }^{3}$, Maedeh Latifi Shirdareh ${ }^{1}$, Kimia Hedayati Marzbali ${ }^{1}$, Narges Gha- \\ fardzadeh Namazi ${ }^{1}$, Ali Ostadzadeh ${ }^{2}$
}

1. Department of Occupational Therapy, School of Health and Paramedical Sciences, Zanjan University of Medical Sciences, Zanjan, Iran. 2. Department of Occupational Therapy, School of Rehabilitation Sciences, Iran University of Medical Sciences, Tehran, Iran.

3. Department of Basic Sciences in Rehabilitation, School of Rehabilitation Sciences, Iran University of Medical Sciences, Tehran, Iran.

\begin{tabular}{|c|c|}
\hline $\begin{array}{l}\text { Use verd devict e sosan } \\
\text { and read the article onine }\end{array}$ & Citation: Pashmdarfard M, Amini M, Sanei SH, Latifi Shirdareh M, Hedayati Marzbali K, Ghafardzadeh Namazi N, et al \\
\hline 口回 & $\begin{array}{l}\text { Prevalence of Flat Foot in Primary School Students Aged 7-12 Years, in Zanjan City, Iran. Journal of Modern Rehabilitation } \\
\text { 2019; 13(4):207-214. http://dx.doi.org/10.32598/JMR.13.4.207 }\end{array}$ \\
\hline$\square$ & dc)" http://dx.doi.org/10.32598/JMR.13.4.207 \\
\hline
\end{tabular}

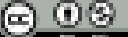

Article info:

Received: 23 Mar 2019

Accepted: 25 Jul 2019

Available Online: 01 Oct 2019

\section{Keywords:}

Flat foot, Prevalence, Primary school students

\section{ABSTRACT}

Introduction: Physical conditions of people are among the essential components of their health. Any structural or physical changes of the human body can affect the performance of the individual. Flat foot is one of the most common problems in musculoskeletal disorders that can be addressed in childhood, and its complications can be reduced by providing appropriate and timely treatments. This study aimed to estimate the prevalence of flat foot in primary school students (aged 7-12 years) in Zanjan City, Iran to improve the effectiveness of interventions.

Materials and Methods: This research was a cross-sectional study to assess the prevalence of flat foot types among 1700 girls and boys students aged 7-12 years in the elementary schools of Zanjan City.

Results: A total of 900 male (53\%) and 800 female (47\%) students participated in this study. The samples' Mean \pm SD age, height, and weight were $9.63 \pm 1.55$ years, $132.93 \pm 13.42 \mathrm{~cm}$, and $32.75 \pm 10.46 \mathrm{~kg}$. The prevalence of different types of flat feet were as follows: $491(28.9 \%)$ children with smooth flat foot, $12(0.7 \%)$ children with rigid flat foot, and $1197(70.4 \%)$ children without any type of flat feet. The ordinal regression model showed that the highest level of the flat foot was observed among the third-grade students with $33 \%$, and the lowest level of the flat foot was among the second-grade students with $26.3 \%$. Weight was the strongest predictor for the flat foot in the students. By $1 \mathrm{~kg}$ weight increase, the probability of flat foot increases by 1.065 times.

Conclusion: The prevalence of foot flat among primary school students in Zanjan City had a high rate. There is a significant relationship between the flat foot and weight, therefore nutritional interventions are necessary for these children. 


\section{Introduction}

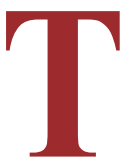

he musculoskeletal system of a person forms the structure and physical dimensions of the individual [1]. If the musculoskeletal system of the child does not develop properly, it can affect the person's future and cause many musculoskeletal problems [2]. The musculoskeletal system in each person consists of various structures, among which the foot is one of the essential structures [3]. The human foot consists of 31 bones connected by 33 joints and more than 100 muscles and ligaments. The correct positioning of these components leads to the formation of a natural foot arch. These bone structures and their ligaments create the medial longitudinal arch, lateral longitudinal arch, and transverse arch of the foot. This structure reduces the forces applied to the body from the ground. Reducing or increasing each of these arches will cause some musculoskeletal issues [3].

The reduction of the medial longitudinal arch of the foot is called the Flat Foot (FF). In people with FF, a large amount of these forces are transferred to the body due to the absence of a medial longitudinal arch, and in the long run can lead to further complications in all joints of the body, especially the spine $[4,5]$. FF is characterized by a flat appearance on the sole of one foot or both, the curvature of the shoe or heel to the inside, pain in the lower extremities and ankle. If you look at the back of a person who has $\mathrm{FF}$, the foot rotation of the heel region will be quite visible [6]. FF, in the long run, can lead to side effects such as calcaneal spur, knee pain, back pain, hammer toe, shin splints, and even headache [7-9].

In many studies, the prevalence of $\mathrm{FF}$ in various age groups has been reported to be between $0.69 \%$ and $28 \%$ [10-13]. In a study that examined the prevalence of FF in Arab countries, the prevalence of this disorder was reported 5\% [13]. In the related studies on the gait style of individuals with or without $\mathrm{FF}$, the individuals with
FF show a higher percentage of the arm and the plantar flexion angle of the ankle than the individuals without it [14-17]. Since FF, as one of the disorders of the musculoskeletal system, leads to future gait disorder, many families and parents of children with FF [18-21] develop anxiety about their children's future. In general, the FF is divided into two types; rigid and flexible. If the medial longitudinal arch of the foot is low in all circumstances (in Weight-Bearing [WB] and Non-Weight Bearing [NWB] conditions), the FF is rigid, and if the medial longitudinal arch of foot only decreases during WB and be normal in NWB condition, the FF will be of a flexible type $[22,23]$.

Karimi et al. (2012) investigated the effect of flat foot and its orthopedic treatment on the energy consumption of individuals with FF. They found that the energy consumption of individuals with FF was much higher than individuals without $\mathrm{FF}$, and the use of medical and associated or thoses can be effective in reducing their energy consumption [24]. FF is one of the common causes of referral of people to orthopedics and rehabilitation specialists. Children with FF do not need surgery, and the presence of FF in children in the first few years after birth can be healthy. The growth of the foot arches occurs over time and the normal growth of children around the age of 5 years, although some experts have considered it normal and permissible to before school age, meaning that if there is FF in children before school age. There is no need for interventions.

Various studies have tried to investigate the prevalence of FF in different parts of the world. The prevalence of this disorder varies in different societies, and studies have reported the effect of gender, age, family history, and Body Mass Index (BMI) in the incidence of the flat foot [25-29]. Therefore, this study aimed to determine the prevalence of FF in primary school students (aged 7-12) in Zanjan city.

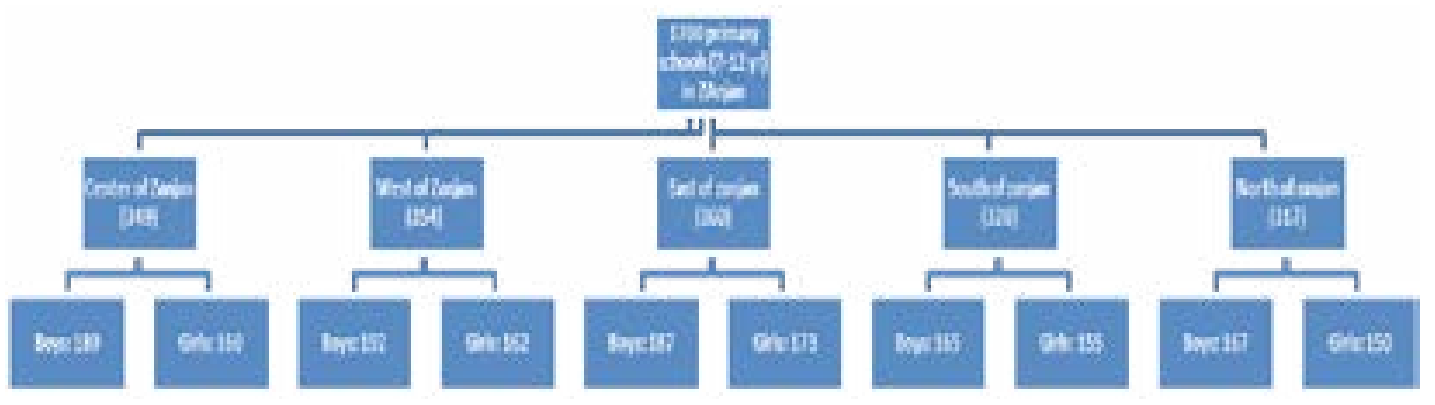

Figure 1. Sampling in primary schools 


\section{Methods}

\section{Study participants}

The participants of this study were all children of primary schools in Zanjan. To choose the samples, we used a multi-stage sampling method. First, the city of Zanjan was divided into 5 regions: north, south, east, west, and center. Then, one girls' school and one boys' school were randomly selected from each region. Finally, after obtaining a letter of introduction from the Zanjan education administration, sampling of these schools was carried out (Figure 1).

\section{Study Procedure}

This cross-sectional study was conducted on 1700 primary school students (aged 7-12 years). To recognize the FF, we should first distinguish the differences between the flexible and rigid FF. Thus, we evaluated the medial longitudinal arch of students' feet in both the WB (standing position) and the NWB (sitting position). In the case of NWB, if the medial longitudinal arch of the students' feet was low, the FF would be the rigid type and requires orthopedic intervention and referral to orthopedic specialists, and if the medial longitudinal arch of the students' feet were not low in NWB but low in the case of WB and the inner angle of the toe was tangent to the ground, the FF would be the flexible type and can be corrected with the medical insole or some corrective movements. If the student lacked any lowered medial longitudinal arch foot in both the WB and NWB, the foot would be normal. In this study, the factors influencing the students' $F F$, such as weight and height, were also considered. Their height and weights were measured by the wall meter and the digital scale, respectively.

\section{Results}

\section{Statistical analysis}

The obtained data were analyzed in proportion to the student population of the city. Out of 1740 surveyed students, data for 40 students were either incomplete or

Table 1. Prevalence of flat foot in elementary schools

\begin{tabular}{|c|c|c|c|c|c|c|c|}
\hline \multirow{2}{*}{ Grade (Class) } & \multicolumn{6}{|c|}{ No. (\%) } & \multirow{2}{*}{ Total } \\
\hline & First & Second & Third & Fourth & Fifth & Sixth & \\
\hline Normal foot & $139(8)$ & 336 (19.7) & $229(13.4)$ & $162(9.5)$ & $167(9.8)$ & $94(5.5)$ & $1197(70.4)$ \\
\hline Flat foot & $57(3.3)$ & $120(7)$ & $147(8.6)$ & $61(3)$ & $76(4.4)$ & $42(2.4)$ & $503(29.5)$ \\
\hline Total & $196(11.3)$ & $456(26.8)$ & $446(26.2)$ & $223(13)$ & $243(14.2)$ & $136(8)$ & 1700 \\
\hline
\end{tabular}

Table 2. Comparing the demographic variables between the two groups of the normal and flat foot $(\mathrm{N}=1700)$

\begin{tabular}{|c|c|c|c|c|}
\hline \multirow{2}{*}{ Demographic Variables } & \multirow{2}{*}{$\begin{array}{c}\text { Type of } \\
\text { Foot }\end{array}$} & \multirow{2}{*}{ Mean $\pm S D$} & \multicolumn{2}{|c|}{ Confidence Interval ( $\mathrm{Cl}=95 \%)$} \\
\hline & & & Lower Bound & Higher Bound \\
\hline \multirow{2}{*}{ Age (y) } & Normal foot & $9.61 \pm 1.565$ & 9.52 & 9.70 \\
\hline & Flat foot & $9.69 \pm 1.515$ & 9.55 & 9.82 \\
\hline \multirow{2}{*}{ Weight $(\mathrm{kg})$} & Normal foot & $30.72 \pm 9.14$ & 30.20 & 31.23 \\
\hline & Flat foot & $35.11 \pm 12.45$ & 34.02 & 36.20 \\
\hline \multirow[b]{2}{*}{ Height $(\mathrm{cm})$} & Normal foot & $132.78 \pm 11.53$ & 132.13 & 133.43 \\
\hline & Flat foot & $134.62 \pm 11.88$ & 133.58 & 135.66 \\
\hline \multirow{2}{*}{$\mathrm{BMI}\left(\mathrm{kg} / \mathrm{m}^{2)}\right.$} & Normal foot & $17.13 \pm 3.13$ & 16.95 & 18.52 \\
\hline & Flat foot & $18.88 \pm 4.16$ & 17.31 & 19.25 \\
\hline
\end{tabular}


Table 3. The predictive value of independent variables

\begin{tabular}{|c|c|c|c|c|c|c|}
\hline & \multirow{2}{*}{ Model } & \multicolumn{2}{|c|}{ Unstandardized Coefficients } & \multirow{2}{*}{$\begin{array}{c}\text { Standardized Coefficients } \\
\text { Beta }\end{array}$} & \multirow{2}{*}{$\mathbf{t}$} & \multirow{2}{*}{ Sig. } \\
\hline & & B & Std. Error & & & \\
\hline \multirow{5}{*}{1} & (Constant) & 1.537 & 0.132 & 1.79 & 11.646 & 0.000 \\
\hline & Age & 0.041 & 0.010 & 0.140 & 4.031 & 0.000 \\
\hline & Gender & -0.031 & 0.022 & -0.034 & -1.406 & 0.160 \\
\hline & Weight & -0.014 & 0.001 & -0.319 & -9.412 & 0.000 \\
\hline & Height & 0.002 & 0.001 & 0.058 & 1.565 & 0.118 \\
\hline
\end{tabular}

outlier, so they were excluded from the sample. Thus, 1700 students aged 7-12 remained in the study. Age, height, and weight variables were measured on a continuous scale. The gender and academic variables were assessed by nominal and sequential scales.

The type of FF was defined as a dependent variable and classified with three options: $0=$ normal foot, $1=$ flexible flat foot, and $2=$ rigid flat foot. Of 1700 students, 12 had rigid FF and 491 flexible FF. Two types of FF were combined, and the dependent variable was presented as the binomial variable with the options of $0=$ normal foot and $1=F F$. In this study, the independent $t$ test was used to compare the mean age and height in two groups of normal foot and FF. The ratio of individuals with $\mathrm{FF}$ was compared between male and female students using the $\mathrm{z}$ statistic. The regression analysis was used to predict the likelihood of flat foot in terms of weight, gender, age, and height variables (since the age of education with age is linear [age +6 ], the logistic equation did not enter). In this way, individuals appeared in the equation with code 0 for normal foot and code 1 for flat foot individuals.

Table 1 presents the demographic characteristic of 1700 students in the city of Zanjan. The highest amount of FF was observed among the third-grade students with $33 \%$ (147 out of 446), and the lowest amount of FF was among the second-grade students with $26.3 \%$ (120 out of 456).

Also, the mean age of the two groups with normal and FF were 9.61 and 9.69 years, respectively. The mean height of the two groups with normal and FF were 138.78 and $134.62 \mathrm{~cm}$, respectively. Also, the mean weight of the two groups of normal and FF were 30.30 and $35.11 \mathrm{~kg}$, respectively. Finally, the mean BMI of the two groups of normal and FF were 17.13 and $18.88 \mathrm{~kg} /$ $\mathrm{m}^{2}$, respectively. Table 2 presents these findings.
Considering the $95 \% \mathrm{CI}$ for the above variables, the mean weight in the FF group compared with the students with the normal foot is $4.39 \mathrm{~kg}$ more, and this difference is statistically significant (two intervals the assurances do not overlap and $\mathrm{P}<0.001)$.

In the logistic model, the contrast was not changed, and the same as the First and Indicator were selected. In block 1 , the output of the logistic regression, which has entered independent variables, $\mathrm{P}$ is too low in Omnibus, which indicates good performance. The $\chi^{2}=96.603$ with a degree of freedom of 5 implies that the overall model is significant for all the variables entered. The HosmerLemeshow test, which is the most consistent fitness test for the SPSS model, shows a strong fit of 0.424 and confirms our model. Weight is the strongest predictor variable for the flat foot between the students, as shown in the column $\operatorname{Exp}(\mathrm{B})$ of the Table below, by increasing the weight of $1 \mathrm{~kg}$, the probability of flat foot increased by 1.065 times (Table 3 ).

\section{Discussion}

The present study aimed to investigate the prevalence of FF among primary school students in the city of Zanjan. In this study, out of 1700 children aged 7-12 years, $491(28.9 \%)$ had flexible FF, and $12(0.7 \%)$ had rigid FF. This study revealed that obesity has a significant relationship with the FF among primary school children so that by increasing $1 \mathrm{~kg}$ weight, the probability of flat foot increased 1.065 times, and with an increase in $1 \mathrm{~kg} /$ $\mathrm{m} 2 \mathrm{BMI}$, the likelihood of FF increased 1.021 times. In the study of Asgari et al., the prevalence of FF and its association with age and gender among students aged 7-12 years old in Tehran was $74 \%$, of which $23 \%$ were mild, $34 \%$ moderate, and $17 \%$ severe [28]. 
Daneshmandi et al. investigated the prevalence of flat foot and its relation to obesity among high school students in Rasht. They found that the prevalence of FF among these students was $23.5 \%$ [29], and obesity was an essential factor in the FF [30]. In another study, conducted by Galini to investigate the prevalence of FF and its relation to obesity in children of Garmsar, the prevalence of FF was $17.82 \%$ [31]. The study of Daneshmandi et al. confirmed the findings of the present study. Homayouni et al. examined the prevalence of FF among Shiraz female children. They reported the prevalence of $\mathrm{FF}$ in these children as $34.9 \%$.

The most conspicuous point in our study was that the highest level of FF was found among the third-grade students with $33 \%$, and the lowest level was among the second-grade students with $26.3 \%$. According to the results, weight gain and exercise were the essential factors in the appearance of FF among the students. In this study, gender had no significant effect on the FF, and the most critical factors were height, weight, and BMI. With increasing each of these items (height, weight, and $\mathrm{BMI}$ ), especially the BMI, the possibility of FF and, consequently, musculoskeletal disorders increased. In another study, Emami et al. examined the prevalence of FF in male children in Shiraz in 2005. They found that $35.7 \%$ of these children had FF [21].

The results of Emami and Homayoni's studies also confirmed the results of the present study that the FF had no relationship with gender and was most affected by physiological factors such as height, weight, and BMI. Since the prevalence of FF in the Arabic countries is $5 \%$, and very low among the young male Turks $(0.69 \%)$, perhaps the race or even the climatic and lifestyle conditions of the people are factors that contribute to musculoskeletal disorders, in particular FF.

\section{Conclusion}

The prevalence of foot flat among primary school students in Zanjan City is very high. Since there was a significant relationship between the flat foot and BMI, nutritional interventions seem necessary for these children. These disorders can affect the quality of life of these individuals by causing physical inability, pain, and, subsequently, stress-related pain and complications. Meanwhile, FF is also a musculoskeletal disorder that causes restrictions for those who have pain in the feet, ankles, legs, and the amount of energy used while walking for people. So it is necessary to prepare proper interventions for these individuals.
Changing the lifestyle, such as doing exercise and observing proper nutrition in childhood, perhaps be beneficial because it leads to losing weight. However, identifying the children with FF and treating this problem in childhood is good to prevent the pain and other musculoskeletal problems in adulthood.

\section{Study Limitations}

There was some lack of cooperation from authorities of education administration, which was resolved by the establishment of an agreement between Zanjan University of Medical Sciences and Education administration in the city.

\section{Study Suggestions}

The educational programs such as teaching corrective movements and observing proper nutrition should be included in the curriculum of primary schools. It is recommended to conduct studies to investigate the relationship between students' nutritional style and their BMI.

\section{Ethical Considerations}

\section{Compliance with ethical guidelines}

The Ethics Committee approved all the study procedures of the Zanjan University of Medical Sciences (Code: ZUMS.REC.1395.296).

\section{Funding}

This study was funded by a grant from Deputy of Research and Technology Zanjan University of Medical Sciences (ZUMS), (ZUMS.REC.1395.296), Iran.

\section{Authors contributions}

Conceptualization: Marzieh Pashmadarfard, Malek Amini; Writing the draft: Marzieh Pashmdarfard; The investigation, resources, data curation: Malek Amini; Formal analysis: Seyed Hassan Saneii; Writing the review and editing: Marzieh Pashmdarfard, Malek Amini.

\section{Conflict of interest}

The authors declared no conflict of interest.

\section{Acknowledgements}

The authors express their gratitude to the school authorities who participated in this study. 


\section{References}

[1] Arshadi R, Rajabi R, Alizadeh MH. [Investigate the correlation between the spinal flexibility with degree of the kyphosis and lordosis (Persian)]. Research on Sport Science. 2007; 5(15):123-32. https:/ / www.sid.ir/fa/journal/ViewPaper.aspx?ID=75753

[2] Torkaman A. [Prevalence of scoliosis in secondary school students of Sanandaj in year 2000 (Persian)]. Scientific Journal of Kurdistan University of Medical Sciences. 2002; 6(3):20-3. https://www.sid.ir/fa/journal/ViewPaper.aspx?ID=12687

[3] Dommisse GF. A re-assessment of patients previously treatedwith intravenous iron dextran. South African Medical Journal. 1972; 45(24): 663-7.

[4] Symington J. Anatomy of acquired flat-foot. Journal of Anatomy and Physiology. 1884; 19(Pt 1):82.2-93. [PMID] [PMCID]

[5] Mauch M, Grau S, Krauss I, Maiwald C, Horstmann T. Foot morphology of normal, underweight and overweight children. International Journal of Obesity. 2008; 32(7):1068-75. [DOI:10.1038/ ijo.2008.52] [PMID]

[6] Domzalski M, Kwapisz AŁ, Król A, Jedrzejewski K. [The role of plantar calcaneonavicular ligament complex in the development of the adult flat foot--anatomical study (Polish)]. Chirurgia Narzadow Ruchu I Ortopedia Polska. 2007; 72(4):265-8. [PMID]

[7] Riccio V, Porpora G, Riccio I. [Pediatric flat foot: A review (Italian)]. La Pediatria Medica e Chirurgica. 2009; 31(5):201-4. [PMID]

[8] Tryfonidis M, Jackson W, Mansour R, Cooke PH, Teh J, Ostlere $\mathrm{S}$, et al. Acquired adult flat foot due to isolated plantar calcaneonavicular (spring) ligament insufficiency with a normal tibialis posterior tendon. Foot and Ankle Surgery. 2008; 14(2):89-95 [DOI:10.1016/j.fas.2007.11.005] [PMID]

[9] Meehan RE, Brage M. Adult acquired flat foot deformity: Clinical and radiographic examination. Foot and Ankle Surgery. 2003; 8(3): 431-52. [DOI:10.1016/S1083-7515(03)00019-6]

[10] Elftman NW. Nonsurgical treatment of adult acquired flat foot deformity. Foot and Ankle Surgery. 2003; 8(3):473-89. [DOI:10.1016/S1083-7515(03)00119-0]

[11] Rose GK, Welton EA, Marshall T. The diagnosis of flat foot in the child. The Journal of Bone and Joint Surgery. British volume. 1985; 67-B(1):71-8. [DOI:10.1302/0301-620X.67B1.3968149] [PMID]

[12] Abdel-Fattah MM, Hassanin MM, Felembane FA, Nassaane MT. Flat foot among Saudi Arabian army recruits: Prevalence and risk factors. Eastern Mediterranean Health Journal. 2006; 12(1-2): 211-7. [PMID]

[13] Pfeiffer M, Kotz R, Ledl T, Hauser G, Sluga M. Prevalence of flat foot in preschool-aged children. Pediatrics. 2006; 118(2):6349. [DOI:10.1542/peds.2005-2126] [PMID]

[14] Takao M, Komatsu F, Oae K, Miyamoto W, Uchio Y, Ochi $\mathrm{M}$, et al. Proximal oblique-domed osteotomy of the first metatarsal for the treatment of hallux valgus associate with flat foot: Effect to the correction of the longitudinal arch of the foot. Archives of Orthopaedic and Trauma Surgery. 2007; 127(8):685-90. [DOI:10.1007/s00402-007-0362-3] [PMID]

[15] Toolan BC. The treatment of failed reconstruction for adult acquired flat foot deformity. Foot and Ankle Clinics. 2003; 8(3):64754. [DOI:10.1016/S1083-7515(03)00118-9]
[16] Hunt AE, Smith RM. Mechanics and control of the flat versus normal foot during the stance phase of walking. Clinical Biomechanics. 2004; 19(4):391-7. [DOI:10.1016/j.clinbiomech.2003.12.010] [PMID]

[17] Fabry G. Clinical practice. Static, axial, and rotational deformities of the lower extremities in children. European Journal of Pediatrics. 2010; 169(5):529-34. [DOI:10.1007/s00431-009-1122-x] [PMID]

[18] Evans AM, Rome K, Peet L. The foot posture index, ankle lunge test, Beighton scale and the lower limb assessment score in healthy children: A reliability study. Journal of Foot and Ankle Research. 2012; 5:1. [DOI:10.1186/1757-1146-5-1] [PMID] [PMCID]

[19] Krul M, van der Wouden JC, Schellevis FG, van SuijlekomSmit LWA, Koes BW. Foot problems in children presented to the family physician: A comparison between 1987 and 2001. Family Practice. 2009; 26(3):174-9. [DOI:10.1093/fampra/cmp018] [PMID]

[20] Lin CJ, Lai KA, Kuan TS, Chou YL. Correlating factors and clinical significance of flexible flatfoot in preschool children. Journal of Pediatric Orthopaedics. 2001; 21(3):378-82. [DOI:10.1097/01241398-200105000-00022] [PMID]

[21] Must A, Dallal GE, Dietz WH. Reference data for obesity: 85th and 95th percentiles of body mass index (wt/ht2) and triceps skinfold thickness. The American Journal of Clinical Nutrition. 1991; 53(4):839-46. [DOI:10.1093/ajcn/53.4.839] [PMID]

[22] Halabchi F, Mazaheri R, Mirshahi M, Abbasian L. Pediatric flexible flatfoot; clinical aspects and algorithmic approach. Iranian Journal of Pediatrics. 2013; 23(3):247-60. [PMID] [PMCID]

[23] Milenković S, Živković M, Bubanj S, Živković D, Stanković $\mathrm{R}$, Bubanj R, et al. Incidence of flat foot in high school students. Facta Universitatis Series: Physical Education and Sport. 2011; 9(3):275-81. http://facta.junis.ni.ac.rs/pe/pe201103/pe20110306.pdf

[24] Karimi MT, Fereshtenejad N, Fatemeh Pol. [The impact of foot insole on the energy consumption of flat foot subjects during walking (Persian)]. Journal of Research in Rehabilitation Sciences. 2011; 7(5):652-60. https://www.sid.ir/fa/journal/ViewPaper.aspx?ID=158733

[25] Alamy B. [An epidemiologic study of flat foot in Iran (Persian)]. Tehran University Medical Journal. 1997; 55(3-4):78-83 http:/ / tumj.tums.ac.ir/article-1-1658-en.htm

[26] Kamali N, Haji Ahmadi M, Janmohamadi N, Kamali AA [Prevalence of flat foot in elementary, guidance and high school students (Babol 2005-2006) (Persian)]. Journal of Babol University of Medical Sciences. 2008; 9(6):50-4. http://jbums.org/article1-2494-fa.html

[27] Eluwa MA, Omini RB, Kpela T, Ekanem TB, Akpantah AO. The incidence of pes planus amongst Akwa Ibom state students in the University of Calabar. The Internet Journal of Forensic Science. 2009; 3(2). https://www.researchgate.net/publication/258975875

[28] Askary Kachoosangy R, Aliabadi F, Ghorbani M. Prevalence of flat foot: Comparison between male and female primary school students. Iranian Rehabilitation Journal. 2013; 11(2):22-4. http:/ /irj.uswr.ac.ir/article-1-300-en.html

[29] Daneshmandi H, Rahnema N, Mehdizadeh R. Relationship between obesity and flatfoot in high-school boys and girls. Inter- 
national Journal of Sports Science and Engineering. 2009; 3(1):439. https://pdfs.semanticscholar.org/b3b9/3257879714cc819a5fc 4c24593d3ebb9c429.pdf

[30] Tachdjian MO. Flexible pes planovalgus (flatfoot). In: Tachdjian MO. Pediatric Orthopedics, Vol. 4. 2nd ed. Philadelphia: W.B. Saunders; 1990. https://books.google.com/books?id=MNsAAAAMAAJ\&dq

[31] Horieh Galini. The relationship between overweight and flat foot in primary school girl students. International Journal of Sport Studies. 2015; 5(5):559-62. 
This Page Intentionally Left Blank 